\title{
LA BIBLIOMETRIA BRASILERA Y SUS ACTORES, 1973-2018
}

\author{
BRAZILIAN BIBLIOMETRICS AND ITS ACTORS, 1973-2018 \\ A BIBLIOMETRIA BRASIELIRA E SEUS ATORES, 1973-2018
}

Rubén Urbizagástegui-A/varado ${ }^{1}$

\begin{abstract}
RESUMO
Analisa-se a rede de coautorias da bibliometria brasileira (BB) dividida em cinco períodos de 1973 a 1980. Verificou-se que no período de 1973 a 1980 a rede é composta por 59 autores com 62 laços. Essas coautorias praticamente quadruplicaram-se no segundo período de 1973 a 1990, atingindo 203 coautorias com 448 laços. 0 crescimento do tamanho das coautorias não é tão acelerado na terceira década, de 1973 a 2000, quando foram atingidas 267 coautorias com 501 laços. Essas coautorias aumentaram para 395 nós com 501 laços na década seguinte e na última década para 375 nós com 501 vínculos. A densidade é a proporção de laços observados na rede em relação com o número máximo de laços possíveis. Nesta rede, a densidade é realmente muito baixa, atingindo $9,5 \%$ no período $1973-1980$, caindo para $2,2 \%$ no período seguinte, $1,4 \%$ entre $1973-2000$ e 0,6\% no período 1973-2010 e 0,7\% no último período. Em certas situações, uma rede está dividida em subgrupos nos quais todos os seus membros estão conectados direta ou indiretamente. No período 1973-1980, havia 14 grupos atuando no BB; ele cresceu para 31 componentes em 12 no período 1973-1990, mas quase dobrou para 65 grupos operando no período 19732000; cresce para 88 grupos diferentes no período 1973-2010, mas diminui para 66 no período 1973-2018.
\end{abstract}

Palavras clave: Bibliometria. Cienciometria. Brasil. Análise de co-autorias. Análise de redes.

\begin{abstract}
The co-authorships network of the Brazilian bibliometrics divided into five periods from 1973 to 1980 is analyzed. It was found that in the period from 1973 to 1980 it is composed of 59 authors with 62 ties. These co-authorships practically quadrupled for the second period from 1973 to 1990, reaching 203 co-authorships with 448 ties. The growth in the size of the co-authorships is not as accelerated in the third decade from 1973 to 2000, when 267 co-authorships were reached with 501 ties. These coauthorships grew to 395 nodes with 501 ties in the following decade and in the last decade to 375 nodes with 501 ties. Density is the ratio of observed ties in the network to the maximum number of possible ties. In this network, the proportion is really very low, reaching $9.5 \%$ in the period $1973-1980$, falling to $2.2 \%$ in the following period, $1.4 \%$ between $1973-2000$ and $0.6 \%$ in the period $1973-2010$ and to $0.7 \%$ in the last period. In certain situations, a network is divided into subgroups in which all its members are directly or indirectly connected. In the period 1973-1980 there were 14 groups acting in the BB, it grew to 31 components in 12 in the period 1973-1990, but almost doubled to 65 groups operating in the period 1973-2000; it grows to 88 different groups in the period 1973-2010, but decreases to 66 in the period 1973-2018.
\end{abstract}

Keywords: Bibliometrics. Informetrics. Scientometrics. Brazil. Coword analysis.

\section{RESUMEN}

Se analiza la red de coautorías de la bibliometría brasileira divididos en cinco periodos de 1973 a 1980. Se encontró que en el periodo de 1973 a 1980 está compuesta de 59 autores con 62 lazos. Estas coautorías prácticamente se cuadruplican para el segundo periodo de 1973 a 1990 alcanzando 203 coautorías con 448 lazos. El crecimiento del tamaño de las coautorías no es tan acelerado en la tercera década de 1973 a 2000 donde se alcanzan 267 coautorías con 501 lazos. Estas coautorías crecen a 395 nodos con 501 lazos en la siguiente década y en la última década a 375 nodos con 501 lazos. La densidad es la proporción de lazos observados en la red en relación con el número máximo de posibles lazos. En esta red la proporción es realmente bajísima alcanzado 9.5\% en el periodo 1973-1980, descendiendo a 2.2\% en el periodo siguiente, $1.4 \%$ entre 1973-2000 y $0.6 \%$ en el periodo $1973-2010$ y a $0.7 \%$ en el último periodo. En ciertas situaciones una red está dividida en subgrupos en la cual todos sus miembros están directa o indirectamente conectados. En el periodo 1973-1980 existían 14 grupos actuando en la BB, crece a 31 componentes en 12 en el periodo 1973-1990, pero casi se duplica a 65 grupos actuantes en el periodo 19732000; crece a 88 grupos diferentes en el periodo 1973-2010, pero disminuye a 66 en el periodo 1973-2018.

Palabras clave: Bibliometría. Informetría. Cientometría. Brasil. Análisis de copalabras.

Artigo submetido em 23/11/2020 e aceito para publicação em 03/12/2020

1 Doutor em Ciência da Informação. Universidade de Califórnia em Riverside, EUA. ORCID https://orcid.org/0000-0001-5014-801X. E-mail: ruben@ucr.edu 


\section{INTRODUCCIÓN}

Lo que caracteriza a las sociedades contemporáneas es un acelerado proceso de adquisición de conocimientos que impacta los mecanismos de transformación social posibilitados por las tecnologías de la información y la comunicación. El desarrollo social no solo proviene del crecimiento de las actividades económicas, sino también de un proceso de transformación propiciado por la producción de literatura especializada y la difusión de esa literatura, por lo tanto, de conocimiento. Sin literatura publicada no hay ciencia que merezca llamarse ciencia, pues, la literatura publicada da cuenta del estado alcanzado por las ciencias. Esto es verdad también para la ciencia de la información brasilera y en especial para ese campo de conocimiento llamado "bibliometría brasileña" y donde se agrupan los estudios sobre las "metrías" realizados por brasileños y otros investigadores de otras nacionalidades, pero publicados por revistas académicas brasileñas. Este trabajo se asienta en la interlocución de esos dos campos del conocimiento y prácticas académicas: la ciencia de la información y la bibliometría brasileña. Se designa como campo al "universo en el que se insertan los agentes e instituciones que producen, reproducen o difunden arte, literatura o ciencia” (BOURDIEU, 2004, p. 21).

Cualquier campo del conocimiento humano es una matriz disciplinaria, una articulación sistemática de un conjunto de paradigmas, coexistiendo en el tiempo, manteniéndose activos y relativamente eficientes en un espacio social histórico. Esto significa que estos paradigmas presentan una diacronía y una sincronía y, por lo tanto, establecen una relación de hegemonía y dependencia. Algunos son dominantes, otros son dominados. Algunos están consolidados, otros son emergentes. Algunos representan la ortodoxia, el conocimiento oficial del campo, otros la heterodoxia, la rebelión contra la ortodoxia, contra el conocimiento oficial establecido. De esa manera, estos paradigmas establecen una relación de conflicto, de lucha para lograr o mantener la hegemonía, mediante la imposición de la "doxa".

Estas luchas son intrínsecas e incluso necesarias para el desarrollo de la ciencia. En realidad, son los mecanismos que hacen progresar cualquier campo científico. Los paradigmas son las estructuras de referencia de los científicos, los modos de teorizar, el modus operatum y el modus operandi que funcionan como metateorías. Un paradigma es el marco estructurado compartido por los miembros de una comunidad científica particular. Este marco incluye expectativas, creencias, beneficios, apreciaciones, valores, técnicas y habilidades compartidas por los miembros de esta comunidad. Esta estructura también se transmite sistemáticamente a los recién llegados, por medio de 
manuales de enseñanza, ilustraciones de casos y principalmente mediante el aprendizaje sistemático. En resumen, un paradigma científico consiste en las "suposiciones que hace una comunidad científica particular a cerca de la realidad y de la naturaleza de una sociedad, suposiciones que no siempre se pueden establecer explícitamente, pero que se transmiten a cada nueva generación de científicos como conocimiento tácito" (MERCER, 1990, p. 15).

Como es bien sabido, fue Khun (1970) quien sugirió que la ciencia es una acción social regulada por una comunidad de científicos que desarrollan paradigmas para guiar sus actividades. Pero la ciencia también es un acto social que tiene lugar en un campo científico particular, en un espacio social en el que existe una lucha competitiva por el monopolio de la "autoridad científica" y el mantenimiento de la "ortodoxia". Por lo tanto, cualquier universo, incluso "el universo puro de la más pura ciencia es también un campo social como cualquier otro, con sus relaciones de poder, con sus monopolios, sus luchas y estrategias, sus intereses y beneficios, pero donde todas estas invariantes están revestidas de una forma específica de competencia" (BOURDIEU, 1973, p. 122). Esta competencia o autoridad científica puede definirse como la capacidad técnica, el poder social para hablar y actuar legítimamente; es decir, de manera autorizada y con autoridad. Esta autoridad le es otorgada socialmente a un agente (un individuo o grupo de individuos) por una comunidad científica mediante diferentes mecanismos.

El campo científico es un espacio social, donde se realiza una especie de juego emergido históricamente poco a poco, de manera muy lenta, que va acompañado de una acumulación de saberes, competencias, técnicas y procedimientos que lo hacen relativamente irreversibles. Existe una acumulación colectiva de recursos poseídos, pero un acceso desigual a esos recursos. Aunque con recortes cronológicos diferentes y aun asuntos temáticos diferentes a la ciencia de la información (RIBEIRO, 2017), diversos autores han realizado aproximaciones a este campo (URBIZAGÁSTEGUI, 1984; PINHEIRO; SILVA, 2008; ARAUJO; ALVARENGA, 2011; LIMA; SOARES; OLIVEIRA, 2011; GRACIO; OLIVEIRA, 2012; MUGNAINI, 2013; URBIZAGÁSTEGUI, 2016). Sin embargo, a pesar de un largo periodo de crecimiento y fortalecimiento desde su implantación en el Brasil (MENEGHINI; PACKER, 2010; URBIZAGÁSTEGUI; RESTREPO, 2017), este campo carece de un estudio de redes de coautorías.

Una red implica un conjunto de relaciones que en sí mismo no significa una conciencia organizadora, ni un sentimiento de pertenencia, ni una frontera, sino una realidad compleja vivida y percibida por los actores sociales (GROSSETTI, 2009). Para facilitar el estudio de las redes, el análisis de redes sociales cuantifica las relaciones entre los actores con el objeto de crear matrices y redes gráficas 
que representen esas relaciones como un todo, y de esa forma analizar las distintas características del sistema de relaciones bajo estudio, indistintamente de la naturaleza de estas relaciones. Se concentra en la red de relaciones, las posiciones funcionalmente diferenciables dentro de éstas, sus procesos dinámicos de adaptación, sus flujos y transacciones (AGUIRRE, 2014). La estructura y las propiedades de las redes sociales evolucionan y cambian con el tiempo en el contexto histórico y social, ya que su composición y constitución están influenciadas por factores económicos, sociales y políticos.

Las redes sociales no solo tienen propiedades topológicas, sino también tienen características dinámicas (NEWMAN; BARABÁSI; WATTS, 2006). Cuando las conexiones y los actores emergen 0 desaparecen de la red indican el cambio de las estructuras con el paso del tiempo. Después de un largo periodo de crecimiento y expansión de los estudios métricos en el Brasil que ya dura 46 años, tal vez sea oportuno revisar esa red de coautorías, su desarrollo y transformación en el tiempo. El uso del análisis de redes sociales aplicado a las coautorías, a las citaciones y a las diversas áreas del conocimiento está ocupando un lugar cada vez más privilegiado en las prácticas académicas. Estos trabajos académicos permiten elaborar mapas de la ciencia que hacen posible identificar y representar gráficamente a las comunidades científicas y el carácter interdisciplinario de las ciencias. Es importante analizar la producción académica de un investigador, también es importante analizar las relaciones con sus pares, su función en la creación y diseminación de conocimiento, la evolución de los grupos de pares en la comunidad científica con la que están comprometidos. Por esa razón, el objetivo de este artículo es estudiar las redes de coautorías formadas por los autores productores de la literatura publicada sobre las "metrías" en el Brasil, desde 1973 hasta diciembre de 2018: un largo periodo de 46 años. Se busca responder a la siguiente pregunta:

¿Quiénes son los investigadores más "prestigiosos" en las investigaciones sobre las "metrías" en el Brasil?

Para responder esa pregunta, este artículo está organizado en seis partes. En la primera se presenta una introducción al tema, se detalla el problema y se formulan las preguntas de investigación. En la segunda se ofrece el referencial teórico sobre los estudios de redes de coautorías en la producción de literaturas, se revisa exhaustivamente la literatura publicada y se explora los modelos propuestos para medir esas coautorías. En la tercera se describe la metodología empleada y la aplicación del modelo de análisis de coautorías escogido con énfasis en la forma de recolección de los datos y la forma de medición de estos. En la cuarta parte se exponen los resultados. En la quinta se proponen las conclusiones y discusiones de los resultados obtenidos. Por último, se presenta la bibliografía revisada para la elaboración de este trabajo. 


\section{MARCO TEÓRICO}

Un campo científico es definido como "una red o una configuración de relaciones objetivas entre posiciones. Estas posiciones están objetivamente definidas, en su existencia y en las determinaciones que imponen sobre sus ocupantes, agentes o instituciones, por su situación presente y potencial (situs) en la estructura de distribución de especies del poder (o capital) cuya posesión ordena el acceso a ventajas específicas que están en juego en el campo, así como por su relación objetiva con otras posiciones (dominación, subordinación, homología, etcétera)" (BOURDIEU; WACQUANT, 2005, p. 150). El campo científico como espacio social está construido de tal modo que "los agentes o los grupos se distribuyen allí en función de su posición en las distribuciones estadísticas de acuerdo con dos principios de diferenciación [...] el capital económico y el capital cultural” (BOURDIEU, 2003, p. 19). Por lo tanto, cuanto más en común sea la posesión de esos capitales por los agentes estos estarán más próximos en la distribución estadística de esas dos dimensiones.

El campo científico es la categoría conceptual que otorga dinámica al habitus, es decir, es el espacio específico en donde los investigadores harán uso de sus capitales culturales. Los capitales culturales son la acumulación de conocimientos y habilidades de los investigadores para posicionarse en el campo y esta posición impacta en la percepción del resto de los agentes que participan en las investigaciones mediante la interacción. De ese modo, en cualquier espacio social los agentes están distribuidos en una primera dimensión, de acuerdo con el volumen global de los capitales (económico y cultural) que poseen, y, en una segunda dimensión, de acuerdo con la estructura de sus capitales, es decir el peso relativo de los capitales económicos y culturales en el volumen global de los capitales (BOURDIEU, 2003). La estructura de un campo, entendido como un espacio de relaciones objetivas entre posiciones definidas es diferente de las redes más o menos duraderas por medio de las cuales se manifiesta a sí mismo.

Es esta estructura la que determina la posibilidad 0 imposibilidad [...] de observar el establecimiento de vinculaciones que expresen y sustenten la existencia de redes. La tarea de la ciencia es descubrir la estructura de la distribución de especies de capital que tiende a determinar la estructura de las posturas adoptadas individual o colectivamente, por medio del análisis de los intereses y disposiciones que condiciona. En el análisis de redes, el estudio de estas estructuras subyacentes ha sido sacrificado en pro del análisis de las vinculaciones particulares (entre agentes o instituciones) y flujos (de información, recursos, servicios etc.) a través de los cuales se hacen visibles (BOURDIEU, 2005, p. 171-172).

En la teoría relacional, una especie de capital es aquello que "es eficaz en un campo determinado, tanto a modo de arma como de asunto de juego en la contienda, que permite a sus poseedores disponer 
de un poder, influencia, y por tanto existir en el campo en consideración, en lugar de ser considerado una cifra desdeñable" (BOURDIEU, 2005, p. 152).

Los investigadores de la bibliometría brasilera movilizan sus capitales para resignificar sus prácticas, a partir de la literatura publicada que, a su vez, funciona como un capital que adquieren y desarrollan, por medio de la capacitación recibida y por su quehacer cotidiano en la docencia o en la investigación practicada. El campo es un espacio social en donde se observan las relaciones de poder, las relaciones de fuerza y las luchas por transformar o conservar ese espacio, que está dotado de leyes propias que no se aplican en otros campos sociales. Pensar en el campo de la bibliometría brasileña es pensar relacionalmente y pensar en que posee autonomía relativa. Un campo se construye con regularidades que pueden ser explícitas o no; se configura y opera con reglas específicas escritas y no escritas. Además, puede ser visto como un lugar en donde los científicos hacen uso de sus habilidades y conocimientos para asegurar su posición, para reforzar su autoridad en el campo y para reproducir la creencia en la doxa del campo.

Un campo científico específico es una especie de conjunto de interacciones y posiciones que se definen en función de la posesión y no-posesión de capitales. Estos capitales se convierten en el instrumento fundamental para actuar en ese campo. Es decir, que las posiciones de los actores se definen en función de la situación actual y potencial en la estructura de distribución de las diferentes especies de capital cuya posición condiciona el acceso a los provechos específicos que están en juego en el campo. El capital es el instrumento para ingresar al campo y para jugar en ese campo. El capital y el campo se necesitan mutuamente, pues, el campo es una construcción analítica, pero que responde a un sistema de relaciones históricas, que refleja un sistema de prácticas sociales. En ese campo, cada posición es siempre relacional, puesto que no se sustenta sobre elementos definidos de forma permanente, sino a partir de las diferencias de "valor" de cada posición social. Las diferencias de valor son cambiantes, son establecidas por los sujetos y por los procesos de codificación que les confiere objetividad.

Existen tres formas básicas de capital: social, económico y cultural, que son convertibles entre sí. Todas éstas pueden convertirse en capital simbólico, a partir del cual se generan las formas de des-conocimiento y reconocimiento. Toda especie de capital tiende en diferentes grados a funcionar como capital simbólico, cuando obtiene un reconocimiento explícito o práctico. El capital simbólico no es una especie particular de capital, sino aquello en lo que se convierte cualquier especie de capital cuando no es reconocida en tanto que capital, es decir, en tanto que fuerza, 
poder o capacidad de explotación, y, por tanto, reconocida como legítima. El capital simbólico es el poder de representar y otorgar valor, importancia social, a las formas de capital. El capital social, es “... el agregado de los recursos reales o potenciales que están ligados a la posesión de una red durable de relaciones de conocimiento y reconocimiento mutuos más o menos institucionalizados" (BOURDIEU, 1986, p. 248). El tratamiento del concepto es instrumental, enfocándose en los beneficios acumulados por el individuo al participar de grupos y la construcción deliberada de la sociabilidad con el propósito de crear este recurso. Se afirma que "Ios beneficios que provienen de la afiliación a un grupo son la base de la solidaridad que los hace posibles" (BOURDIEU, 1986, p. 249). Las redes sociales no son datos naturales y deben construirse a través de estrategias de inversión orientadas hacia la institucionalización de las relaciones de los grupos, utilizadas como una fuente segura de beneficios.

\section{MATERIAL Y METODOS}

Como unidades de análisis fueron tomados cada uno de los artículos publicados en revistas académicas, capítulos de libros y trabajos presentados en congresos que trataron algunos de los aspectos de los estudios métricos (bibliometría, cienciometría, informetría, etc.) o las aplicaciones de estas técnicas en una disciplina o subcampo determinado en el Brasil o por brasileños que publicaron documentos sobre este asunto fuera del Brasil. Se excluyeron los autores de libros, tesis, monografías y literatura gris por dos razones. Primero, porque los libros comienzan como artículos publicados en revistas especializadas; y segundo, porque los libros, las tesis, monografías y literatura gris no son indexadas en muchas de las bases de datos bibliográficas consultadas para esta investigación. El periodo cubierto va desde los primeros trabajos publicados a inicios de la década de los 70s hasta diciembre de 2018.

Para recolectar los datos fueron efectuadas búsquedas usando los términos listados en el Anexo A en sus diferentes acepciones idiomáticas (inglés, francés, alemán, portugués, español, etc.) y en múltiples combinaciones booleanas en los títulos, palabras clave y resúmenes de las bases de datos bibliográficas y portales de bibliotecas listadas en el Anexo B. Las referencias identificadas fueron después exportadas a EndNote X8 para la elaboración de una base de datos sobre el asunto. Posteriormente, fue realizada una minuciosa lectura de cada uno de los documentos identificados en la búsqueda, dedicando especial atención a cada referencia efectuada en el documento leído. Después 
cada referencia relativa al asunto de investigación era confrontada con la base de datos e incorporada, si no había sido identificada en la búsqueda anterior. Lógicamente las referencias duplicadas fueron eliminadas, manteniéndose solamente una referencia no repetida.

La identificación de la pertinencia del documento fue una tarea ardua y difícil, porque con mucha frecuencia las palabras clave fueron insuficientes y a veces falsos indicativos. Para identificar a los autores brasileños se analizó la afiliación institucional de cada autor en cada referencia recuperada. Muchas veces fue necesario consultar la Plataforma Lattes para realizar esta verificación o buscar los "currículo vitae" de los autores, y en no pocas situaciones, se realizó minería de textos y consultas individuales vía correo electrónico. La nacionalidad y la afiliación institucional fueron también indagadas, por medio de mensajes personales enviados al correo electrónico del investigador identificado. Con toda esa estrategia y la lectura minuciosa de muchos de los artículos identificados fue producida la base de datos (que sirve de base al objeto de esta investigación) que contiene referencias de artículos de revistas, capítulos de libros, comunicaciones presentadas en congresos, una que otra nota editorial y cartas enviadas a los editores de las revistas académicas. Esta base de datos especializada ha estado en construcción permanente por un periodo de más de ocho años.

Para el análisis de la red de coautorías se consideraron las relaciones entre los coautores como no-dirigidas. Como los autores publican en colaboración, se considera la existencia de reciprocidad en las respectivas publicaciones, por lo tanto, se estimaron las siguientes medidas de análisis de las informaciones recolectadas: la densidad de la red, que permite la visualización de la intensidad de la cooperación en la red analizada, pues, muestra la potencialidad de la red en términos del flujo de informaciones. La distancia que indica el esfuerzo que hace un autor para alcanzar a otro autor en la red y mide la distancia media de los autores para llegar a todos Ios demás autores. El grado de centralidad indica el número de conexiones que salen o parten desde un autor, es decir, la cantidad de conexiones que éste tiene con sus pares. El grado de intermediación que mide el grado en que un autor actúa como puente entre otros autores de la red, ya que analizando a todos los pares de autores se identifica al autor que se localiza en el camino más corto entre otros dos autores en la red. El grado de cercanía que se usa para conocer la capacidad que tiene un autor de colaborar con los demás autores definiéndose como la capacidad que en promedio tiene un autor de estar más cerca a los otros autores en la red, es decir, la distancia promedio existente entre un autor y los otros autores de la red. Para analizar la 
red de coautorías, los datos organizados en EndNote X8 fueron leídos y preparados con BibExcel y luego exportados a Excel. Con el paquete Statnet de R (HANDKOCK, et al., 2003) se estimó la densidad y los grados de centralidad. Las tablas resultantes fueron analizadas y un reporte con la interpretación de esos resultados fue creado para cada autor colaborador de la literatura recogida y organizada en Endnote 8X.

\section{RESULTADOS}

La Tabla 1 presenta los valores de las medidas topográficas encontradas en la red de coautorías de la bibliometría brasileña (BB). En el periodo 1973-1980, la red de coautorías de la BB está compuesta de 59 autores con 62 lazos. Estas coautorías prácticamente se cuadruplican para el segundo periodo de 1973 a 1990 alcanzando 203 coautorías con 448 lazos. El crecimiento del tamaño de las coautorías no es tan acelerado en la tercera década de 1973 a 2000 alcanzando 267 coautorías con 501 lazos. Estas coautorías crecen a 395 nodos con 501 lazos en la siguiente década y en la última década a 375 nodos con 501 lazos.

La densidad es la proporción de lazos observados en la red en relación con el número máximo de posibles lazos. En este caso la proporción es realmente bajísima, alcanzado 9.5\% en el periodo 1973-1980, descendiendo a $2.2 \%$ en el periodo siguiente, $1.4 \%$ entre $1973-2000$ y $0.6 \%$ en el periodo $1973-2010$ y a $0.7 \%$ en el último periodo. Por lo tanto, la red estaba mucho más compacta en el periodo 1973-1980 y esta compacticidad desciende en los últimos periodos.

En ciertas situaciones una red está dividida en grupos distintos. Un grupo es un subgrupo de la red en la cual todos sus miembros están directa o indirectamente conectados. En el periodo 1973-1980 existían 14 grupos actuando en la BB, creció a 31 componentes en el periodo 1973-1990, pero casi se duplica a 65 grupos actuantes en el periodo 1973-2000; creció a 88 grupos diferentes en el periodo 1973-2010, pero disminuyó a 66 en el periodo 1973-2018.

En las cinco décadas que se estudiaron el diámetro de la red varía de 4 a 13. El diámetro de la red es apenas el más largo de los caminos más cortos que unen a todos los pares de nodos y refleja el flujo de recursos que discurren en la red. Esta es apenas de 4 nodos entre 1973-1980, pero conforme la red va creciendo también el diámetro se va diversificando para alcanzar su mayor dimensión de 13 entre 1973-2018. 
Tabla 1 - Características topográficas de la red de coautorías de la bibliometría brasilera

\begin{tabular}{llllll}
\hline Medidas & $\mathbf{1 9 7 3 - 1 9 8 0}$ & $\mathbf{1 9 7 3 - 1 9 9 0}$ & $\mathbf{1 9 7 3 - 2 0 0 0}$ & $\mathbf{1 9 7 3 - 2 0 1 0}$ & $\mathbf{1 9 7 3 - 2 0 1 8}$ \\
\hline Tamaño & $59-62$ & $203-448$ & $267-501$ & $395-501$ & $375-501$ \\
Densidad & 0.09468 & 0.0368 & 0.014 & 0.0064 & 0.007 \\
Componentes & 14 & 31 & 65 & 88 & 66 \\
Diámetro & 4 & 5 & 6 & 12 & 13 \\
Transitividad & 0.98285 & 0.9421 & 0.882 & 0.5195 & 0.364 \\
Distancia media & 1.64435 & 1.829 & 1.763 & 5.011 & 4.5996 \\
Grado medio & 5.492 & 4.603 & 3.753 & 2.537 & 2.672 \\
Compacticidad & 0.111 & 0.051 & 0.021 & 0.02085 & 0.038 \\
Reciprocidad & 1 & 1 & 1 & 1 & 1 \\
\hline
\end{tabular}

Fonte: Autoria propia

La transitividad se refiere a la proporción de triángulos cerrados (triadas en las que se observan tres lazos). Estas triadas cerradas son mayores en el periodo 1973-1980 (98.3\%); disminuye en el periodo 1973-1990 (27.1\%); vuelve a crecer en el periodo 1973-2000 (88.2\%) y decrece nuevamente en el periodo 1973-2010 (52\%).

La distancia media representa la media de la distancia geodésica en la red. Esto significa que el flujo de recursos eran más expeditivos y con menos impedimentos estructurales en el periodo 19731980 (distancia media de 1.6), es mayor en el periodo 1973-1990 (3.5). Nuevamente es más expedito en el periodo 1973-2000 (1.8) y es más estructuralmente problemático en el periodo 1973-2010 y 1973-2018 (distancia media de 5).

El grado medio indica cuantos lazos en promedio tienen los nodos en la red. El promedio de Ios lazos indican mayor interdependencia entre los coautores. Esta interdependencia era mayor en el periodo 1973-1980 (5.5) y se va debilitando conforme crece el tamaño de la red de coautorías. Es decir, cuanto mayor el tamaño de la red, tanto la densidad como el grado medio de la red se reducen.

La compacticidad se refiere al hecho de que una red puede estar bastante concentrada 0 desconcentrada, es decir, dispersa. Los menores valores indican que en promedio las distancias son más cortas, en otras palabras, la red es más compacta. En el caso de la red de coautorías de la BB en el periodo 1973-2000 y siguiente (1973-2010) esta es mucho más compacta que en periodos posteriores. Es decir, conforme la red crece y se diversifica se convierte en menos compacta y más dispersa. 
La Tabla 2 presenta las características de dominancia e igualitarismo presentes en la red. El grado de centralización indica que esta red es dominada por muy pocos autores centrales en los cinco periodos bajo estudio. Esto es reconfirmado por el desvío patrón del grado de centralización de la red. El grado de intermediación indica también que pocos autores funcionan como puentes en la red de coautorías de la BB. Por eso la desviación estandariza es tan elevada.

El grado de proximidad evidencia esa dispersión extensiva de coautores en la red y por eso también el desvío patrón es atípico y diferenciado. El egienvector indica que la red es dominada por pocos nodos centrales que controlan el flujo de coautorías en la red. Esta dominancia ha ido más concentrada y mayor entre 1973-1980, aumentando paulatinamente desde la década de los 80 para llegar a ser más dominante aun en todo el periodo de estudio de la red.

Tabla 2 - Características de dominancia e igualitarismo

\begin{tabular}{llllll}
\hline $\begin{array}{l}\text { Medidas de } \\
\text { Centralización }\end{array}$ & $\mathbf{1 9 7 3 - 1 9 8 0}$ & $\mathbf{1 9 7 3 - 1 9 9 0}$ & $\mathbf{1 9 7 3 - 2 0 0 0}$ & $\mathbf{1 9 7 3 - 2 0 1 0}$ & $\mathbf{1 9 7 3 - 2 0 1 8}$ \\
\hline Grado & 0.18118 & 0.091 & 0.061 & 0.039 & 0.049 \\
Intermediación & 0.035 & 0.013 & 0.004 & 0.039 & 0.037 \\
Proximidad & 0.0098 & 0.002 & 0.001 & 0.001 & 0.001 \\
Eigenvector & 0.754 & 0.887 & 0.947 & 0.968 & 0.969 \\
Sd del grado & 5.935 & 5.0265 & 3.8786 & 2.129 & 2.547 \\
Sd de intermediación & 10.759 & 17.1028 & 15.0996 & 275.137 & 337.691 \\
Sd de proximidad & 5.9112 & 0.0001 & 0.001 & 0.001 & 0.001 \\
Sd del eigenvector & 0.446 & 0.3327 & 0.235 & 0.133 & 0.116 \\
\hline
\end{tabular}

Fonte: Autoria propia

\subsection{Red de coautorías en el periodo 1973-1980}

La Figura 1 muestra los 14 componentes de la red de coautorías de la bibliometría brasilera para el periodo de 1973-1980. Puede notarse claramente la existencia de un subgrupo cohesivo, hasta otros tres grupos de 4 a 6 actores poco extensivos y grupos de tres y dos relaciones funcionales. 
Figura 1 - Red de coautorías de la BB, 1973-1980

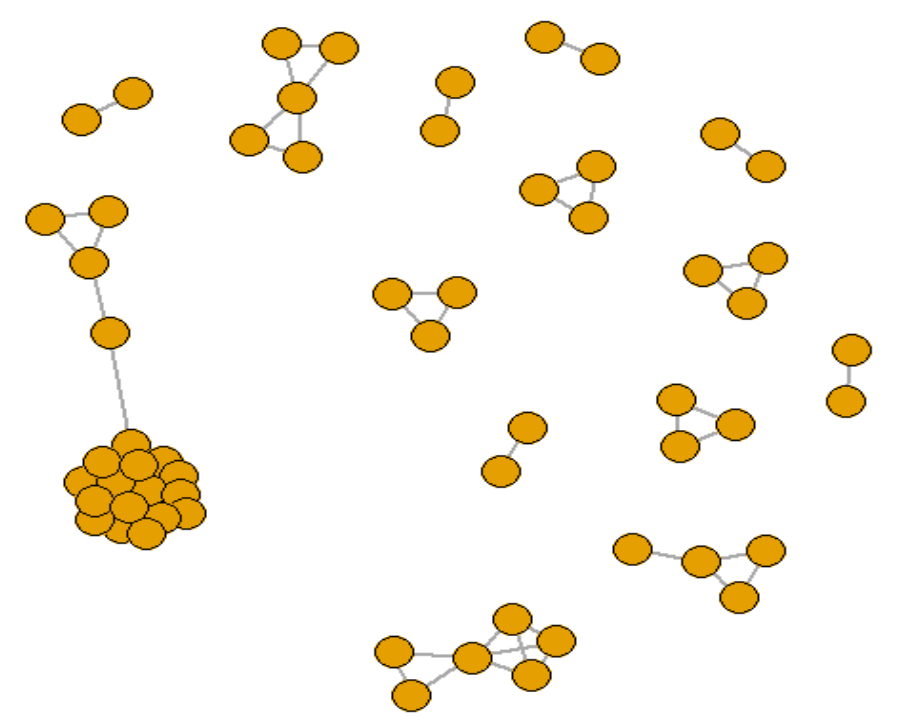

Fonte: Fuente propia

La centralidad mide en qué medida los vínculos de una red de coautorías se concentran en un solo autor 0 grupo de autores. La medida más simple es el grado de centralidad (Ver Tabla 1) que cuenta la cantidad de lazos que tiene cada autor y donde el autor más central es aquel que tiene más lazos. Entre 1973-1980, la autora Margarida Pinto Oliveira era la más central seguida de un grupo de otros 15 autores cuyos nombres pueden ser fácilmente leíbles (aquellos con grado igual a 15) en la Tabla 3. 
Tabla 3 - Grado de los autores en el periodo 1973-1980

\begin{tabular}{lcccc}
\hline Autores & Grado & Intermediación & $\begin{array}{c}\text { Centralidad } \\
\text { Cercanía }\end{array}$ & Eigenvector \\
\hline Oliveira, Margarida Pinto & 16 & 60 & 0.0255 & 1.0000 \\
Fonseca, E. M. C. & 15 & 0 & 0.0249 & 0.9958 \\
Fontes, H. S. & 15 & 0 & 0.0249 & 0.9958 \\
Fixina, A. M. & 15 & 0 & 0.0249 & 0.9958 \\
Moreira, Ney Paulo & 15 & 0 & 0.0249 & 0.9958 \\
Rocha, M. L. P. da & 15 & 0 & 0.0249 & 0.9958 \\
Santana, Claudio Moreira & 15 & 0 & 0.0249 & 0.9958 \\
Piedade, T. F. & 15 & 0 & 0.0249 & 0.9958 \\
Melo, N. T. & 15 & 0 & 0.0249 & 0.9958 \\
Miranda, S. G. & 15 & 0 & 0.0249 & 0.9958 \\
Barros, M. A. & 15 & 0 & 0.0249 & 0.9958 \\
Borba, G. L. G. & 15 & 0 & 0.0249 & 0.9958 \\
Aragão, I.R.B.Neves & 15 & 0 & 0.0249 & 0.9958 \\
Campos, A. C. C. de & 15 & 0 & 0.0249 & 0.9958 \\
Bulcão, L. A. & 15 & 0 & 0.0249 & 0.9958 \\
Souza, M. C. B. P. & 15 & 0 & 0.0249 & 0.9958 \\
Pasquarelli, Maria Luiza Rigo & 5 & 6 & 0.0185 & 0.0000 \\
Noronha, Daisy Pires & 4 & 0 & 0.0182 & 0.0000 \\
Carvalho, Neide de & 3 & 0 & 0.0185 & 0.0000 \\
Pedreira, Rosa E.L.A & 3 & 0 & 0.0185 & 0.0000 \\
Lima, Ida Maria Cardoso & 3 & 2 & 0.0178 & 0.0000 \\
Carvalho, Maria de L.B.de & 3 & 34 & 0.0247 & 0.0045 \\
Quemel, María Angelica R. & 3 & 0 & 0.0185 & 0.0000 \\
Caldeira, Paulo da Terra & 2 & 48 & 0.0248 & 0.0669 \\
\hline
\end{tabular}

Fonte: Autoria propia

El grado de intermediación captura la importancia de los autores en el flujo de la red. Si un autor $C$ se encuentra en la ruta más corta entre los autores $A$ y $B$, significa que el autor C es importante para el flujo eficiente de informaciones entre los autores A y B. Por lo tanto, la intermediación da cuenta de las rutas más cortas en que se encuentra cada autor en la red. Cuanto mayor sea la separación de un autor en la red, mas importante será para el flujo de información en la red. La intermediación es una medida pensada para capturar la correduría, es decir, el hecho de que un autor se encuentra en una posición intermedia entre los caminos más cortos que unen a dos autores en la red. Por ejemplo, en una red que disemina información los autores con mayor 
grado de intermediación tendrán control sobre los mensajes que circulan en la red. Por otro lado, su remoción de la red tendría un fuerte impacto sobre la circulación de la información en la red. En la red de coautorías del periodo 1973-1980, Margarida Pinto Oliveira era la autora con mayor grado de intermediación, pero en la intermediación también eran importantes Paulo da Terra Caldeira y Maria de L. B. de Carvalho.

La centralidad de cercanía indica los caminos más cortos entre los coautores. La distancia entre dos autores se mide como la longitud del camino más corto entre ellos. Para un determinado autor, la distancia es la distancia promedio de ese autor a todos los demás autores. Es una medida pensada para capturar la cercanía o proximidad de un autor a los otros autores. Los autores con valores más bajos pueden tener mejor acceso a la información circulando en la red o también pueden tener más influencia sobre otros autores en la red. Entre 1973-1980, la autora Margarida Pinto Oliveira era la de mayor cercanía seguida de un grupo de otros 15 autores cuyos nombres pueden ser fácilmente leíbles (aquellos con cercanía igual a 0.0249) en la Tabla 1, pero también eran importantes Paulo da Terra Caldeira (cercanía $=0.0248$ ) y María de L. B. de Carvalho (cercanía igual a 0.0247).

La centralidad eigenvector toma en cuenta el poder de los alters. Es una medida de la importancia de un autor en la red. Si un autor es considerado importante y está conectado a otros autores importantes, este será percibido aun como más importante que uno que está conectado a autores con contactos menos influyentes. Es decir, las conexiones con los autores que son influyentes van a otorgarle a otro autor más influencia que las conexiones que tenga a los autores menos influyentes. En el periodo de 1973 a1980, la autora Margarida Pinto Oliveira era la más prestigiosa seguida de un grupo de otros 15 autores cuyos nombres pueden ser fácilmente leíbles (aquellos con eigenvector igual a 0.9958) en la Tabla 3.

\subsection{Red de coautorías en el periodo 1973-1990}

La Figura 2 muestra los 31 componentes de la red de coautorías de la bibliometría brasileña para el periodo de 1973-1990. Puede notarse claramente la existencia de dos subgrupos cohesivos, otros subgrupos poco extensivos de 4 y 5 actores y grupos de tres y dos relaciones funcionales. 
Figura 2 - Red de coautorías de la BB, 1973-1990

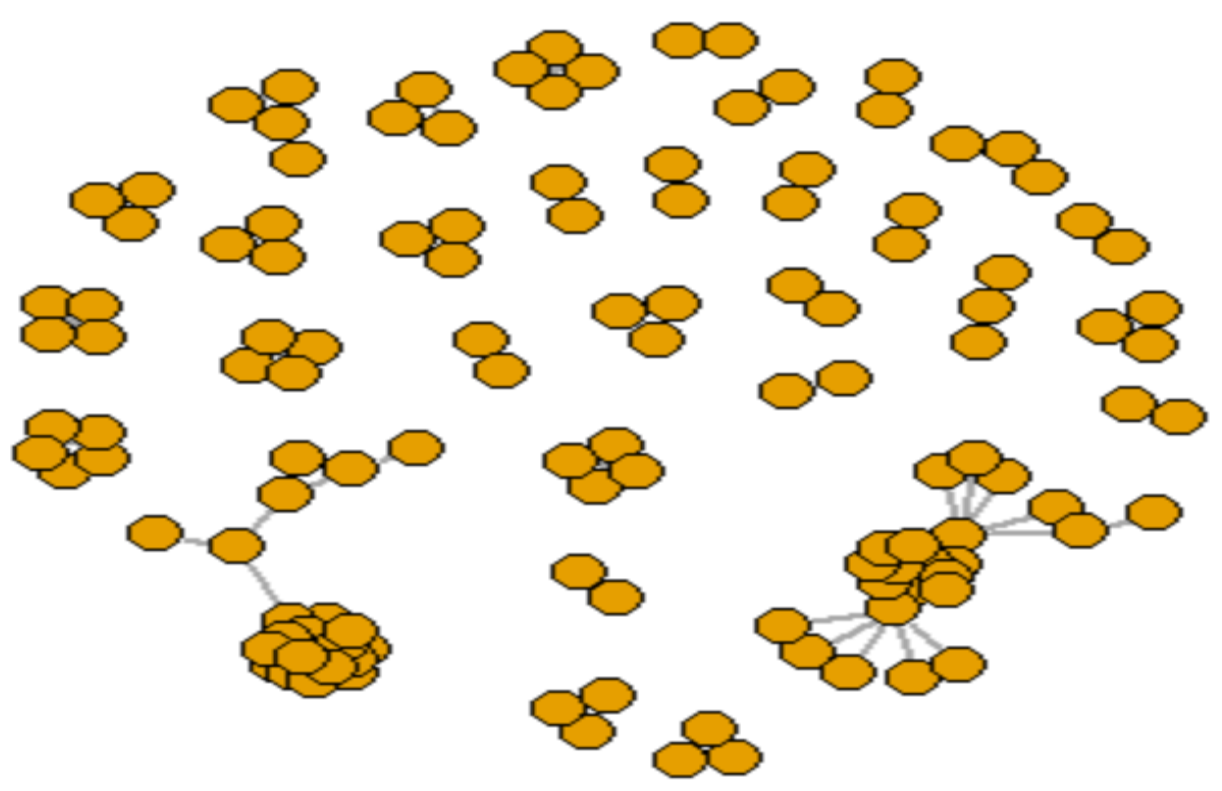

Fonte: Autoria propia

Entre 1973-1990, aparecen Maria Luiza Rigo Pasquarelli, Margarida Pinto Oliveira y Daisy Pires Noronha como las figuras más centrales (con grado igual a 16) seguida de un grupo de otros 15 autores cuyos nombres se listan en la Tabla 4 (aquellos con grado igual a 15). Estas tres autoras y en el mismo orden acaparan la intermediación como una medida pensada para capturar la correduría, es decir, el hecho de que un autor se encuentra en una posición intermedia entre los caminos más cortos que unen a dos o más autores en la red, pero en la intermediación también continúan siendo importantes Paulo da Terra Caldeira y Maria de L. B. de Carvalho. En relación con la centralidad de cercanía, los 32 autores listados en la Tabla 4, son los más cercanos, porque no muestran mucha diferencia en sus valores de evaluación. Con respecto a la centralidad eigenvector, es decir, las conexiones con los autores que son influyentes que van a otorgarle a otro autor más influencia que las conexiones que tenga a los autores menos influyentes, la autora Margarida Pinto Oliveira continua como la más prestigiosa seguida de un grupo de otros 15 autores cuyos nombres pueden ser fácilmente leíbles (aquellos con eigenvector igual a 0.9958). 
Tabla 4 - Grado de los autores en el periodo 1973-1990

\begin{tabular}{lllll}
\hline Centralidad & Grado & Intermediación & $\begin{array}{l}\text { Centralidad d } \\
\text { Cercanía }\end{array}$ & \\
\hline Pasquarelli, Maria Luiza Rigo & 16 & 105.0 & 0.0096 & 0.0000 \\
Oliveira, Margarida Pinto & 16 & 90.0 & 0.0095 & 1.0000 \\
Noronha, Daisy Pires & 16 & 91.5 & 0.0096 & 0.0000 \\
Fonseca, E. M. C. & 15 & 0.00 & 0.0095 & 0.9958 \\
Fontes, H. S. & 15 & 0.00 & 0.0095 & 0.9958 \\
Fixina, A. M. & 15 & 0.00 & 0.0095 & 0.9958 \\
Rocha, M. L. P. da & 15 & 0.00 & 0.0095 & 0.9958 \\
Santana, Claudio Moreira & 15 & 0.00 & 0.0095 & 0.9958 \\
Piedade, T. F. & 15 & 0.00 & 0.0095 & 0.9958 \\
Melo, N. T. & 15 & 0.00 & 0.0095 & 0.9958 \\
Miranda, S. G. & 15 & 0.00 & 0.0095 & 0.9958 \\
Moreira, Ney Paulo & 15 & 0.00 & 0.0095 & 0.9958 \\
Aragao, Iracema R.B.N. & 15 & 0.00 & 0.0095 & 0.9958 \\
Barros, M. A. & 15 & 0.00 & 0.0095 & 0.9958 \\
Bulcao, L. A. & 15 & 0.00 & 0.0095 & 0.9958 \\
Campos, A. C. C. de & 15 & 0.00 & 0.0095 & 0.9958 \\
Borba, G. L. G. & 15 & 0.00 & 0.0095 & 0.9958 \\
Souza, M. C. B. P. & 15 & 0.00 & 0.0095 & 0.9958 \\
Imperatriz, Ines M. de M. & 11 & 0.00 & 0.0096 & 0.0000 \\
Toloi, N. & 11 & 0.00 & 0.0096 & 0.0000 \\
Plaza, R. T. T. & 11 & 0.00 & 0.0096 & 0.0000 \\
Lobo, M. P. & 11 & 0.00 & 0.0096 & 0.0000 \\
Krzyzanowski, Rosaly Favero & 11 & 0.00 & 0.0096 & 0.0000 \\
Arruda, R. M. A. & 11 & 0.00 & 0.0096 & 0.0000 \\
Almeida, M. dos S. & 11 & 0.00 & 0.0096 & 0.0000 \\
Andrade, E. & 11 & 0.00 & 0.0096 & 0.0000 \\
Bonesio, M. C. M. & 11 & 0.00 & 0.0096 & 0.0000 \\
Zapparoll, M. C. de M. & 11 & 0.00 & 0.0096 & 0.0000 \\
Caldeira, Paulo da Terra & 3 & 84.0 & 0.0095 & 0.0672 \\
Carvalho, Maria de L.B. de & 3 & 54.0 & 0.0095 & 0.0003 \\
Poblacion, Dinah Aguiar & 3 & 21.0 & 0.0095 & 0.0000 \\
Carvalho, Maria Martha de & 3 & 20.0 & 0.0095 & 0.0003 \\
\hline
\end{tabular}




\subsection{Red de coautorías en el periodo 1973-2000}

Para el periodo de 1973-2000 la red creció hasta tener 65 componentes de coautorías. Puede notarse claramente la existencia de cuatro grandes subgrupos cohesivos, otros subgrupos poco extensivos de 4 a 8 relaciones y muchos grupos de tres o dos relaciones funcionales (Ver Figura 3).

Figura 3 - Red de coautorías de la BB, 1973-2000

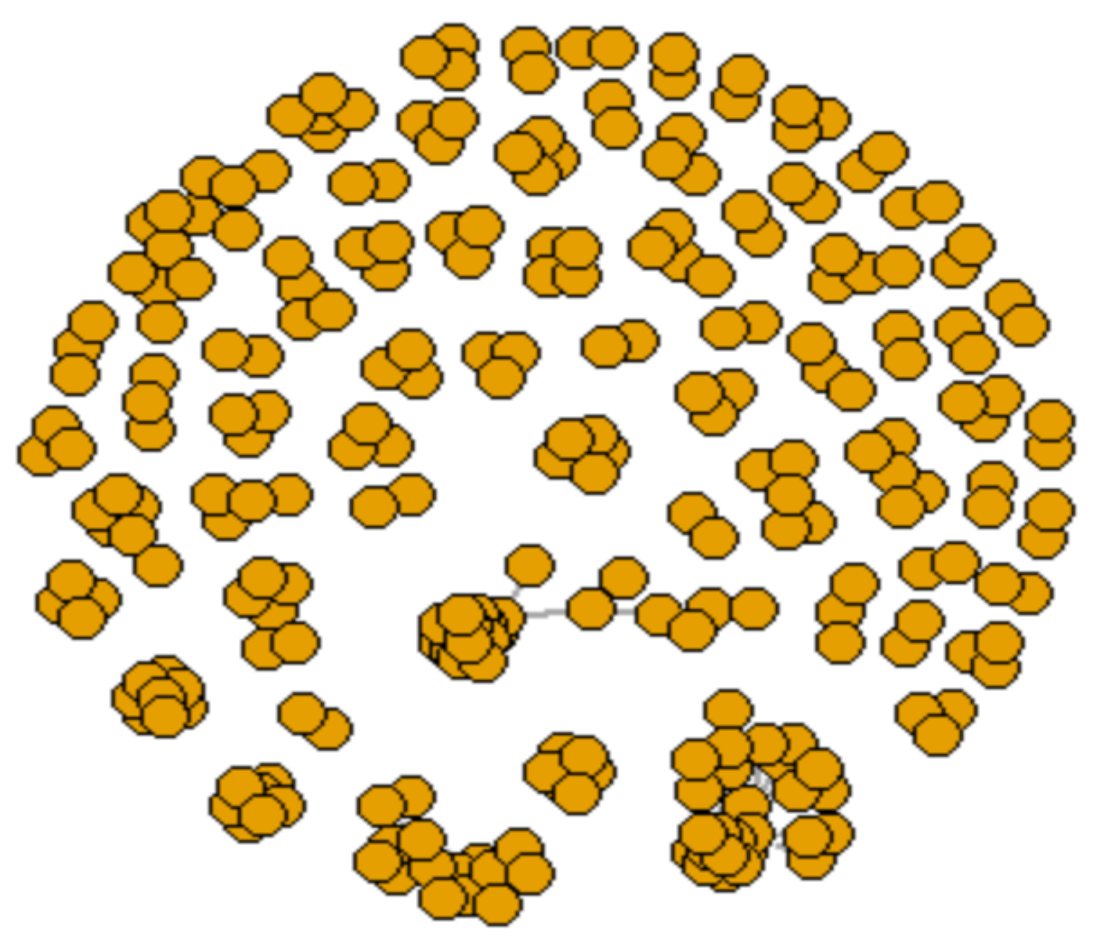

Fonte: Autoría propia

Entre 1973-2000 se altera ligeramente los grados de centralidad, Daisy Pires Noronha es la figura más central, seguida de Margarida Pinto Oliveira (grado igual a 20) y María Luiza Rigo Pasquarelli, como las figuras más centrales (con grado igual a 16). Hay también un grupo de otros 15 autores cuyos nombres pueden ser fácilmente leíbles (aquellos con grado igual a 15) en la Tabla 5.

La intermediación proporciona información acerca de la posición de intermediario en las trayectorias más cortas entre los autores (distancias geodésicas). Los autores con mayor intermediación poseen gran relevancia dentro de la red, ya que controlan las comunicaciones más importantes circulando en la red. En este periodo Daisy Pires Noronha y Margarida Pinto Oliveira son las investigadoras que 
concentran mayor puntaje en intermediación. Sin embargo, Maria Luiza Rigo Pasquarelli y Paulo da Terra Caldeira, son investigadores que no pueden ser ignorados en esta intermediación. La cercanía ofrece información acerca de la distancia media de cada autor con relación a cada uno del resto de los autores. Esto significa que, a mayor cercanía, mayor facilidad de acceso al resto de los autores de la red. En relación con la centralidad de cercanía todos los autores listados en la Tabla 5 parecen compartir esta característica. Los valores son muy cercanos y casi los mismos para todos los autores.

La centralidad eigenvector es una medida de la importancia de un autor en la red. Si un autor es considerado importante y está conectado a otros autores igualmente importantes, este será percibido aun como más importante que uno que está conectado a autores con contactos menos influyentes. Es decir, las conexiones con los autores que son influyentes van a otorgarle a otro autor más influencia que las conexiones que tenga a los autores menos influyentes. Es una medida razonable de la posición de ventaja que tiene un autor dentro de la red. En el periodo de 1973 a 2000, los 13 autores cuyos nombres pueden ser fácilmente leíbles (aquellos con eigenvector igual a 1.000) en la Tabla 5, son los que muestran esta característica. Sin embargo, los autores Margarida Pinto Oliveira, Ney Paulo Moreria y G. L. G. Borba, no pueden ser ignorados en este ítem pues son centrales en la red. 
Tabla 5 - Grado de los autores en el periodo 1973-2000

\begin{tabular}{|c|c|c|c|c|}
\hline Autores & Grado & Interme diación & $\begin{array}{l}\text { Centralidad } \\
\text { Cercanía }\end{array}$ & Eigenvector \\
\hline Noronha, Daisy Pires & 20 & 160.0 & 0.0041 & 0.0000 \\
\hline Oliveira, Margarida Pinto & 16 & 111.0 & 0.0041 & 0.9524 \\
\hline Pasquarelli, Maria Luiza Rigo & 16 & 89.5 & 0.0041 & 0.0000 \\
\hline Fontes, H. S. & 15 & 0.69 & 0.0041 & 1.0000 \\
\hline Fonseca, E. M. C. & 15 & 0.69 & 0.0041 & 1.0000 \\
\hline Fixina, A. M. & 15 & 0.69 & 0.0041 & 1.0000 \\
\hline Piedade, T. F. & 15 & 0.69 & 0.0041 & 1.0000 \\
\hline Santana, Claudio Moreira & 15 & 0.69 & 0.0041 & 1.0000 \\
\hline Rocha, M. L. P. da & 15 & 0.69 & 0.0041 & 1.0000 \\
\hline Melo, N. T. & 15 & 0.69 & 0.0041 & 1.0000 \\
\hline Miranda, S. G. & 15 & 0.69 & 0.0041 & 1.0000 \\
\hline Aragao, Iracema R.B.N. & 15 & 0.69 & 0.0041 & 1.0000 \\
\hline Barros, M. A. & 15 & 0.69 & 0.0041 & 1.0000 \\
\hline Campos, A. C. C. de & 15 & 0.69 & 0.0041 & 1.0000 \\
\hline Bulcao, L. A. & 15 & 0.69 & 0.0041 & 1.0000 \\
\hline Souza, M. C. B. P. & 15 & 0.69 & 0.0041 & 1.0000 \\
\hline Moreira, Ney Paulo & 14 & 0.00 & 0.0041 & 0.9442 \\
\hline Borba, G. L. G. & 13 & 0.00 & 0.0041 & 0.8798 \\
\hline Imperatriz, Ines M. de M. & 11 & 0.00 & 0.0041 & 0.0000 \\
\hline Krzyzanowski, Rosaly Favero & 11 & 0.00 & 0.0041 & 0.0000 \\
\hline Plaza, R. T. T. & 11 & 0.00 & 0.0041 & 0.0000 \\
\hline Toloi, N. & 11 & 0.00 & 0.0041 & 0.0000 \\
\hline Lobo, M. P. & 11 & 0.00 & 0.0041 & 0.0000 \\
\hline Arruda, R. M. A. & 11 & 0.00 & 0.0041 & 0.0000 \\
\hline Almeida, M. dos S. & 11 & 0.00 & 0.0041 & 0.0000 \\
\hline Andrade, E. & 11 & 0.00 & 0.0041 & 0.0000 \\
\hline Bonesio, M. C. M. & 11 & 0.00 & 0.0041 & 0.0000 \\
\hline Zapparoll, M. C. de M. & 11 & 0.00 & 0.0041 & 0.0000 \\
\hline Faria, Leandro I. Lopes de & 9 & 25.25 & 0.0039 & 0.0000 \\
\hline Quoniam, Luc & 9 & 20.75 & 0.0039 & 0.0000 \\
\hline Santos, Raimundo N.M. dos & 8 & 30.5 & 0.0039 & 0.0000 \\
\hline Caldeira, Paulo da Terra & 3 & 89.0 & 0.0041 & 0.0651 \\
\hline Carvalho, Maria de L.B. de & 3 & 57.0 & 0.0041 & 0.0044 \\
\hline Población, Dinah Aguiar & 6 & 34.0 & 0.0041 & 0.0000 \\
\hline Fonseca, Lucia & 6 & 31.0 & 0.0039 & 0.0000 \\
\hline Meis, Leopoldo de & 6 & 28.5 & 0.0039 & 0.0000 \\
\hline Leta, Jacqueline & 4 & 10.5 & 0.0039 & 0.0000 \\
\hline
\end{tabular}




\subsection{Red de coautorías en el periodo 1973-2010}

La Figura 4 muestra los 88 componentes de la red de coautorías de la bibliometría brasileña para el periodo de 1973-2010. Puede notarse claramente la existencia de varios subgrupos cohesivos, subgrupos poco extensivos y grupos de tres y dos relaciones funcionales.

Figura 4 - Red de coautorías de la BB, 1973-2010

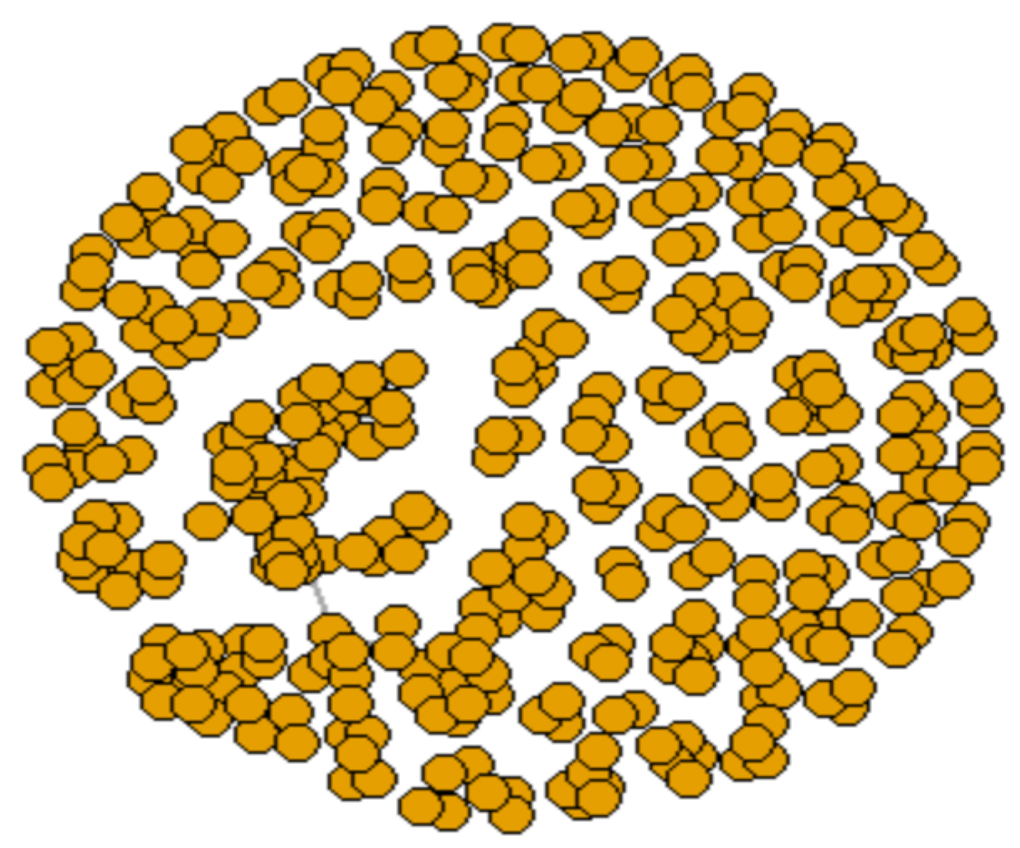

Fonte: Autoría propia

Entre 1973-2010 se alteran los grados de centralidad; aparecen nuevos actores (Leandro I. Lopes de Faria, Maria C. P. Innocentini Hayashi, Luc Quoniam y así sucesivamente (Ver Tabla 6). Desaparecen las autoras Margarida Pinto Oliveira y María Luiza Rigo Pasquarelli, centrales en las redes en los periodos anteriores. La única que aún permanece es Daisy Pires Noronha. En general aparecen nuevos autores que desplazan de la red a las figuras centrales anteriores. Básicamente en este periodo la mayor parte de la red se renueva.

Si la intermediación proporciona información acerca de la posición de intermediario en las trayectorias más cortas entre los autores (distancias geodésicas). Los autores con mayor intermediación poseen gran relevancia dentro de la red, ya que controlan las comunicaciones más importantes que 
circulan en la red. En este periodo Rogerio Mugnaini es el autor que concentra mayor puntaje en intermediación, a pesar de tener bajo grado de centralidad. Luego viene Luc Quoniam con alto grado de centralidad. También Dinah Aguiar Población muestra alta intermediación; igualmente Daisy Pires Noronha.

Como la cercanía ofrece información acerca de la distancia media de cada autor con relación a cada uno del resto de los autores. Esto significa que, a mayor cercanía, mayor facilidad de acceso al resto de los autores de la red. En relación con la centralidad de cercanía todos los autores listados en la Tabla 6 parecen compartir esta característica. Los valores son muy cercanos y casi los mismos para todos los autores.

La centralidad eigenvector es una medida de la importancia de un autor en la red. Si un autor es considerado importante y está conectado a otros autores igualmente importantes, este será percibido, aun como más importante que uno que está conectado a autores con contactos menos influyentes. Es decir, las conexiones con los autores que son influyentes van a otorgarle a otro autor más influencia que las conexiones que tenga a los autores menos influyentes. Es una medida razonable de la posición de ventaja que tiene un autor dentro de la red. En el periodo de 1973 a 2010, Luc Quoniam es el autor que lidera en esta característica, seguido de Leandro I. Lopes de Faria, y bastante alejado aparece Wanda A. Machado Hoffmann. 
Tabla 6 - Grado de los autores en el periodo 1973-2010

\begin{tabular}{lllll}
\hline Autores & Grado & Intermediación & $\begin{array}{l}\text { Centralidad } \\
\text { Cercanía }\end{array}$ & Eigenvector \\
\hline Faria, Leandro I. Lopes de & 18 & 1115.5 & 0.0033 & 0.9165 \\
Hayashi, Maria C. P. Innocentini & 15 & 567.2 & 0.0033 & 0.5969 \\
Quoniam, Luc & 14 & 2584.6 & 0.0033 & 1.0000 \\
Hayashi, Carlos Roberto Massao & 11 & 234.9 & 0.0033 & 0.5480 \\
Noronha, Daisy Pires & 11 & 1445.5 & 0.0033 & 0.0037 \\
Leta, Jacqueline & 11 & 843.5 & 0.0033 & 0.0001 \\
Riccio, Edson Luiz & 10 & 534.0 & 0.0033 & 0.6419 \\
Hoffmann, Wanda A. Machado & 10 & 480.8 & 0.0033 & 0.7018 \\
Gregolin, Jose Angelo Rodrigues & 9 & 117.7 & 0.0033 & 0.5814 \\
Penteado Filho, Roberto de Camargo & 8 & 12.0 & 0.0033 & 0.6401 \\
Santos, Raimundo N. Macedo dos & 8 & 633.0 & 0.0033 & 0.0001 \\
Cruz, Ana Paula Capuano da & 7 & 9.0 & 0.0026 & 0.0000 \\
Cipriano, Robinson & 7 & --- & 0.0033 & 0.6021 \\
Gomes, Ubiraci & 7 & --- & 0.0033 & 0.6021 \\
Fonseca Junior, Wilson Correa da & 7 & --- & 0.0033 & 0.6021 \\
Boutin, Eric & 7 & --- & 0.0033 & 0.6021 \\
Oliveira, Ely Francina Tannuri de & 7 & 19.0 & 0.0026 & 0.0000 \\
Rossoni, Luciano & 7 & 21.5 & 0.0026 & 0.0000 \\
Vilches, Henrique & 7 & --- & 0.0026 & 0.6021 \\
Guarido Filho, Edson Ronaldo & 6 & 10.0 & 0.0033 & 0.0000 \\
Bello, Suzelei Faria & 6 & 95.8 & 0.0033 & 0.2042 \\
Ferreira Junior, Amarilio & 6 & 43.6 & 0.0033 & 0.3582 \\
Ensslin, Sandra Rolim & 6 & 99.3 & 0.0027 & 0.0000 \\
Espejo, Marcia M. dos S. Bortolocci & 6 & 3.0 & 0.0026 & 0.0000 \\
Cardoso, Ricardo Lopes & 6 & 231.5 & 0.0033 & 0.1202 \\
Igami, Mery Piedad Zamudio & 6 & 850.0 & 0.0033 & 0.0008 \\
Figueira, Ivan & 6 & 316.5 & 0.0033 & 0.0001 \\
Santos, Acacia Aparecida Angeli dos & 6 & 6.5 & 0.0026 & 0.0000 \\
Mugnaini, Rogerio & 6 & 3051.0 & 0.0033 & 0.1422 \\
Andrade Neto, Mariano Lopes de & 6 & 5.0 & 0.0026 & 0.0000 \\
Silva, Marcia Regina da & 6 & 31.8 & 0.0033 & 0.3663 \\
Poblacion, Dinah Aguiar & - & 1627.0 & 0.0033 & 0.0195 \\
Meneghini, Rogerio & - & 1444.0 & 0.0033 & 0.0218 \\
Fonseca, Lucia & - & 1403.0 & 0.0033 & 0.0029 \\
Meis, Leopoldo de & - & 1279.0 & 0.0033 & 0.0004 \\
Packer, Abel Laerte & - & ---- & 0.0033 & 0.0247 \\
\hline
\end{tabular}

Fonte: Autoría propia 


\subsection{Red de coautorías en el periodo 1973-2018}

La Figura 5 muestra los 66 componentes de la red de coautorías de la bibliometría brasileña para el periodo de 1973-2018. Puede notarse claramente la existencia de muchos subgrupos cohesivos, hasta tres otros grupos poco extensivos y grupos de tres y dos relaciones funcionales.

Figura 5 - Red de coautorías de la BB, 1973-2018

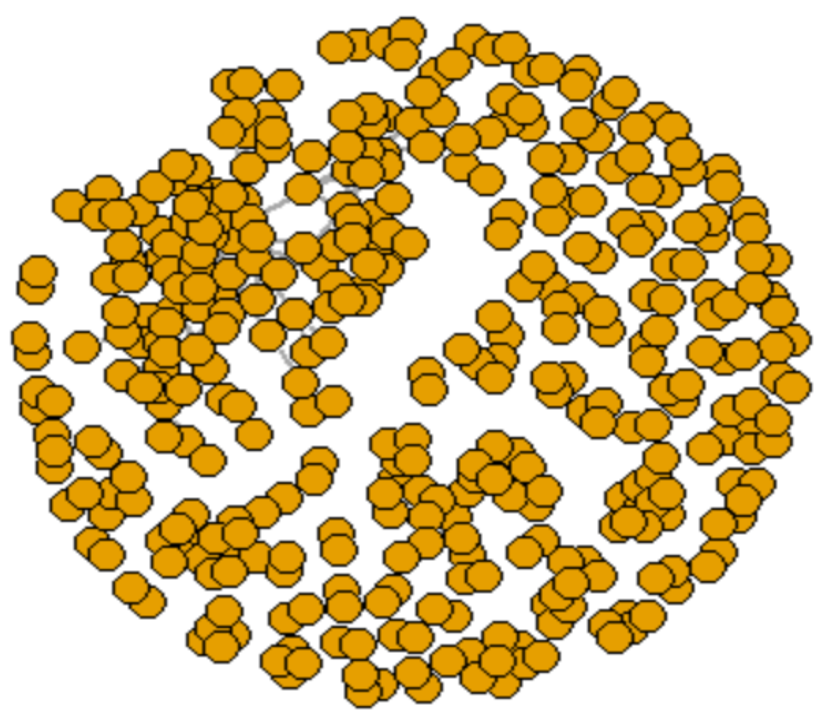

Fonte: Autoría propia

Entre 1973-2018 se alteran ligeramente los grados de centralidad, pero los actores siguen siendo los mismos: aparecen Maria C. P. Innocentini Hayashi con el mayor grado de centralidad seguido de Carlos Roberto Masao Hayashi, Leandro I. Lopes de Faria, Sandra Rolim Ensslin y LuC Quoniam y así sucesivamente (Ver Tabla 7). Como la intermediación proporciona información acerca de la posición de intermediario en las trayectorias más cortas entre los autores, aquellos con mayor intermediación poseen gran relevancia dentro de la red, ya que controlan las comunicaciones más importantes circulando en la red. En este periodo Carlos Roberto Massao Hayashi, es quien concentra mayor puntaje en intermediación; luego viene Leilah Santiago Bufrem, Rogerio Mugnaini y aparece Raimundo Nonato Macedo dos Santos.

La cercanía ofrece información acerca de la distancia media de cada autor con relación a cada uno del resto de los autores. Esto significa que, a mayor cercanía, mayor facilidad de acceso al resto de los autores de la red. En relación con la centralidad de cercanía todos los autores listados en la Tabla 7 parecen compartir esta característica. Los valores son muy cercanos y casi los mismos para todos los autores. 
Si un autor es considerado importante y está conectado con otros autores igualmente importantes, éste será percibido aun como más importante que uno que está conectado a autores con contactos menos influyentes. Es decir, las conexiones con los autores que son influyentes van a otorgarle a otro autor más influencia que las conexiones que tenga a los autores menos influyentes. Es una medida razonable de la posición de ventaja que tiene un autor dentro de la red. En el periodo de 1973-2018, Maria C. P. Innocentini Hayashi seguido de Carlos Roberto Masao Hayashi son Ios autores considerados más importantes; luego viene Leandro Innocentini Lopes de Faria y bastante alejado Wanda A. Machado Hoffmann y Luc Quoniam.

Tabla 7 - Grado de los autores en el periodo 1973-2018

\begin{tabular}{lllll}
\hline Autores & Grado & Intermediación & Centralida d & Eigenvector \\
& & & Cercanía & \\
\hline Hayashi, Maria C. P. Innocentini & 21 & 1269.65 & 0.0041 & 1.0000 \\
Hayashi, Carlos Roberto Massao & 18 & 2659.14 & 0.0041 & 0.9596 \\
Faria, Leandro Innocentini Lopes de & 15 & 1784.46 & 0.0040 & 0.7348 \\
Ensslin, Sandra Rolim & 14 & 90.40 & 0.0028 & 0.0000 \\
Quoniam, Luc & 14 & 875.68 & 0.0040 & 0.4650 \\
Santos, Raimundo N. Macedo dos & 12 & 2140.76 & 0.0040 & 0.0000 \\
Bufrem, Leilah Santiago & 11 & 2468.70 & 0.0041 & 0.1026 \\
Oliveira, Ely Francina Tannuri de & 11 & 1747.11 & 0.0041 & 0.2150 \\
Vanz, Samile Andrea de Souza & 11 & 1207.08 & 0.0040 & 0.0137 \\
Gracio, Maria Claudia Cabrini & 10 & 1971.94 & 0.0041 & 0.2454 \\
Ensslin, Leonardo & 9 & 23.07 & 0.0028 & 0.0000 \\
Caregnato, Sonia Elisa & 9 & 977.72 & 0.0040 & 0.0086 \\
Kneipp, Jordana Marques & 9 & 16.83 & 0.0027 & 0.0000 \\
Ribeiro, Henrique Cesar Melo & 9 & 147.17 & 0.0029 & 0.0000 \\
Costa, Benny Kramer & 8 & 160.17 & 0.0029 & 0.0000 \\
Moura, Ana Maria Mielniczuk de & 8 & 822.82 & 0.0040 & 0.0134 \\
Hoffmann, Wanda A. Machado & 8 & 388.43 & 0.0040 & 0.5979 \\
Leta, Jacqueline & 8 & 1112.00 & 0.0040 & 0.1962 \\
Mugnaini, Rogerio & 8 & 2260.51 & 0.0041 & 0.3486 \\
Serra, Fernando Antonio Ribeiro & 8 & 95.83 & 0.0029 & 0.0000 \\
Stumpf, Ida Regina Chitto & 7 & 158.45 & 0.0040 & 0.0060 \\
Amaral, Roniberto Morato do & 7 & 7.98 & 0.0040 & 0.3662 \\
Silva, Fabio Mascarenhas e & 7 & 158.26 & 0.0040 & 0.0277 \\
Filippo, Daniela de & -- & 1180.32 & 0.0040 & 0.0496 \\
Ferraz, Maria Cristina Comunian & -- & ---- & 0.0040 & 0.4295 \\
Bello, Suzelei Faria & -- & ---- & 0.0040 & 0.3939 \\
Rigolin, Camila Carneiro Dias & -- & ---- & 0.0040 & 0.3531 \\
Marcelo, Julia Fernandes & -- & ---- & 0.0040 & 0.3531 \\
\hline
\end{tabular}




\section{DISCUSIÓN Y CONCLUSIÓN}

En la identificación de autores de prestigio que conforman la red de coautorías de la bibliometría brasileña, se observa tres etapas. La primera etapa que va desde 1973 hasta 2000 con muy pocas modificaciones en los autores con mayor grado de centralidad (cercanía, proximidad e intermediación). Esta etapa puede ser explicada por la estructura de un campo definida como una red, o configuración, de relaciones objetivas entre las posiciones de los actores (BOURDIEU; WACQUANT, 1992). Para analizar los campos de producción científica Bourdieu (1985a, 1992) introduce una noción compleja que lleva en consideración las diferentes formas de capital: capital social, capital cultural y capital económico, con los cuales los actores se posicionan en un espacio social, o topografía. Dentro de los campos específicos los actores compiten por posiciones sociales y esta competencia da lugar a una estructura social que, en la forma de una topografía social, posiciona a los actores, de acuerdo con las cantidades y combinaciones de los capitales poseídos y disponibles por los actores (BOURDIEU, 1989). La topografía está construida de tal manera que los agentes que ocupan posiciones similares o vecinas se colocan en posiciones similares (BOURDIEU, 1989), lo que a su vez hace que dichos actores sean más propensos a colaborar entre ellos porque desarrollan disposiciones, intereses y hábitus similares. Estas disposiciones, intereses y "hábitus" similares podrían haber sido generados por los cursos de bibliometría impartidos en los programas de postgrado del IBICT, pues la mayoría de los autores con mayores grados de centralidad hasta 2000 son egresados de o ligados a este programa, profesores universitarios o consultores del CNPQ. Según Urbizagastegui y Restrepo (2016), la literatura sobre bibliometría en este periodo no crece, pero se mantiene estable. Esta es la etapa de los exploradores del campo, por eso los grados de intermediación y cercanía están ausentes o son bajos. Estos investigadores no son necesariamente los que descubren nuevos hechos. Su trabajo se basa principalmente en los asuntos ya descubiertos y en las técnicas experimentales desarrolladas por otros. La razón es que, en el momento en que entran al campo científico, los hechos no son suficientemente conocidos o no son bien comprendidos. Sin embargo, lo que podría ser considerado como inexactitudes en la descripción de los hechos estudiados, en realidad, son hipótesis de trabajo que son explorados por estos autores (SCHNEIDER, 2009). Esta etapa se caracteriza por los grados de intermediación y cercanía ausentes o bajos. Conforme las coautorías crecen y se transforman en más densas esto grados de intermediación y cercanía también irán modificándose. 
Paulatinamente los cursos de técnicas bibliométricas se amplían y son introducidos en otros programas de formación académica (Brasilia, Minas Gerais, São Paulo-Campinas y otros), pero esos programas solo se ofrecen en el nivel de maestría, pero como muy bien lo afirman Población y Noronha (2002), con el paso de los años esos programas se convirtieron en el polo generador de la producción científica brasilera. Este parece ser el caso de la bibliometría brasilera hasta 2010. Los autores de prestigio identificados se modifican, nuevos autores entran a la competencia por la autoridad en el campo, pero es evidente que:

[...] el interés en bibliometría ha aumentado considerablemente desde la década de 1970 [...], ya sea debido al aumento de los cursos de postgrado en el país [...], ya sea por el crecimiento cuantitativo y cualitativo de las revistas científicas [...], pero este crecimiento se ha producido en todas las ciencias (MATTOS; JOB, 2008).

Esta década es, también, cuando la bibliometría brasileña alcanza su forma exponencial, es decir, la producción académica explosiona (URBIZAGÁSTEGUI; RESTREPO, 2016) y parte de esta producción también será hecha en colaboración. Este impulso en la formación de redes de coautorías y los autores que consolidan su autoridad es estimulado por estos programas y los programas de doctorado que toman fuerza en esta década y donde ya se oficializaron los cursos de bibliometría. Pero el crecimiento todavía es lento y las redes de coautorías comienzan a crecer impulsadas ahora por los orientadores de tesis. Una nueva camada de colaboradores aparece en el escenario bibliométrico brasileño. Crece la intermediación, porque los orientadores de tesis se transforman en colaboradores de las tesis propiciadas por los orientados que más tarde se convertirán en competidores y por eso la cercanía permanece baja o inexistente, pero crece la intermediación, porque los orientadores se convierten en intermediarios de esa colaboración, pero no hay mucha cercanía entre ambos en términos de colaboración espontánea. Por eso la cercanía continua baja o inexistente.

Al finalizar el año 2018, esta misma camada de autores logran afianzarse y legitimar su autoridad en el campo. Se apropiaron del campo y consolidaron su dominio en el campo de la bibliometría brasileña atrincherados en la docencia de los cursos de postgrado y propiciado por el "habitus" definido como el conjunto de características adquiridas (saberes, experiencias, conocimientos) y aprehendidas socialmente que adjudican a los agentes las habilidades necesarias para ser más o menos competentes y competitivos al interior del campo. Los campos son estructuras de relaciones entre agentes sociales que se expresan en espacios cuya característica determinante está constituida por el capital como conjunto de privilegios, poderes y prerrogativas conseguidos por los agentes en luchas anteriores que les posibilitan la acumulación de capitales (simbólicos, sociales, culturales, etc.). Esta dinámica 
social explica las diferentes estrategias desarrolladas por los agentes en procura de la conservación o subversión de la "autoridad" propias del campo de la bibliometría brasileña, pues los agentes son portadores de capital y la posición que ocupan en el campo en virtud del volumen y estructura del capital que poseen, tenderán a orientar sus actividades hacia la conservación de la distribución del capital 0 hacia la subversión de esa distribución propiciando así la creación de una jerarquía de colaboradores. Esta jerarquía se refiere al grado en que las participaciones producen grupos de posiciones sociales en términos de diferencias de autoridad y prestigio: Ios prominentes como la élite (con mayor grado de centralidad) y los otros como la periferia (con menor grado de centralidad). Los elementos de segmentación son relacionalmente independientes, pero en la medida que las posiciones sociales están vinculadas a diferentes estados de autoridad y prestigio, aparecen las jerarquías. Sin embargo, se observa nuevamente que a pesar de que la intermediación crece (porque los orientadores se transforman en colaboradores de las tesis de sus orientados que se publican convertidos en artículos o ponencias en congresos) la cercanía continua baja.

Para finalizar, es necesario concordar en que reconocer la dimensión social de las estrategias científicas

[...] no significa reducir las demostraciones científicas a meras exhibiciones retóricas; invocar el papel del capital simbólico como arma y apuesta de las luchas científicas no significa convertir la persecución del beneficio simbólico en el fin o la razón de ser exclusivos de los comportamientos científicos; desvelar la lógica agonística del funcionamiento del campo científico no significa ignorar que la competencia no excluye la complementariedad o la cooperación, y que, de la competencia y de la competición mismas, pueden surgir, en unas condiciones determinadas, Ios "controles" y los "intereses de conocimiento" (Bourdieu, 1997, p. 87).

\section{REFERÊNCIAS}

AGUIRRE, J.L. Actores, relaciones y estructuras: introducción al análisis de redes sociales. Hologramática: Facultad de Ciencias Sociales, UNLZ, v.1, n.20, p.161-187, 2014.

ARAÚJO, R.F.; ALVARENGA, L. A bibliometria na pesquisa científica da pós-graduação brasileira de 1987 a 2007. Encontros Bibli: revista eletrônica de biblioteconomia e ciência da informação, v.16, n.31, p.51-70, 2011.

BOURDIEU, P. Os usos sociais da ciência: por uma sociologia clínica do campo científico. Tradução de Denice Barbara Catani. São Paulo: Unesp, 2004.

BOURDIEU, P.; WACQUANT, L. Una invitación a la Sociología reflexiva. Buenos Aires: Siglo XXI Editores Argentina, 2005. 
BOURDIEU, P.; WACQUANT, L. An invitation to reflexive sociology. Chicago: University of Chicago press, 1992.

BOURDIEU, P. 0 campo científico. In: BOURDIEU, P.. Sociologia. São Paulo: Ática, 1973, p. 122-155.

BOURDIEU, P. Las formas de capital. In. Handbook of theory and research for the sociology of education, New York : Greenwood Press, 1986. Traducido por Rubén Urbizagástegui Alvarado. Disponível em: <https://www.academia.edu/1360865/LAS_FORMAS_DE_CAPITAL>_Acesso em: 13 jun. 2020.

BOURDIEU, P. Razões práticas: sobre a teoria da ação. 4a. ed. Campinas, SP : Papirus Editora, 2003.

BOURDIEU, P. Razones prácticas: sobre la teoría de la acción. Barcelona : Editorial Anagrama, 1997.

GRÁCIO, M.C.C.; OLIVEIRA, E.F.T. de. A inserção e o impacto internacional da pesquisa brasileira em "estudos métricos": uma análise na base Scopus. Tendências da Pesquisa Brasileira em Ciência da Informação, v.5, n.1, 2012.

GROSSETTI, M. ¿Qué es una relación social?: Un conjunto de mediaciones diádicas. Redes: Revista Hispana para el Análisis de Redes Sociales, n.16, p.1-19, 2009.

KUHN, T. The structure of scientific revolutions. 2.ed. Chicago: University Of Chicago Press, 1970.

HANDCOCK, M.; HUNTER, D.; BUTTS, C; GOODREAU, S.; KRIVITSKY, P.; MORRIS, M. statnet: Software tools for the Statistical Modeling of Network Data, 2003. URL http://statnetproject.org

LIMA, L.S.; SOARES, C.F.; OLIVEIRA, E.F.T. de. Investigação da Produção Científica no tema "Estudos Métricos" na base de dados Brapci: uma análise bibliométrica. EDICIC, v.1, n.4, p.299-310, 2011.

MENEGHINI, R.; PACKER, A.L. The extent of multidisciplinary authorship of articles of scientometrics and bibliometrics in Brazil. Interciencia, v.35, n.7, p.510-514, 2010.

MERCER, J.R. The impact of changing paradigms of disability on metal retardation in the Year 2000. In: ROWITZ, L. (Ed.). Mental retardation in the year 2000. New York: Springer, 1992, p.15-38.

MUGNAINI, R. 40 anos de bibliometria no Brasil: da bibliografia estatística à avaliação da produção científica nacional. In: Bibliometria e cientometria: reflexões teóricas e interfaces. São Carlos: Pedro e João Editores, 2013, p.37-58.

NEWMAN, M.; BARABASI, A.; WATTS, D. The structure and dynamics of networks. Princeton University Press, 2006.

PINHEIR0, L.V.R.; SILVA, G.S. Cartografia histórica e conceitual da bibliometria/informetria no Brasil. In CONFERENCIA IBERO-AMERICANA DE PUBLICAÇÕES ELETRONICAS NO CONTEXTO DA COMUNICAÇÃO CIENTIFICA, II., 2, 2008, Rio de Janeiro, Anais... Rio de Janeiro: CIPECC, 2008.

POBLACION, D.A.; NORONHA, D.P. Produção da literatura "branca" e "cinzenta" pelos docentes/ doutores dos programas de pós-graduação em ciência da informação no Brasil. Ciência da Informação, v.31, n.2, p.98-106, 2002. 
RIBEIRO, H.C.M. Bibliometría: quince años de análisis de la producción académica en revistas científicas brasileñas. Biblios, n.69, 2017. Disponível em: <https://biblios.pitt.edu/ojs/index.php/ biblios/article/view/393/316> Acesso em: 13 jun., 2020.

SCHNEIDER, A.M. Four stages of a scientific discipline: four types of scientist. Trends in Biochemical Sciences, v.34, n.5, p.217-223, 2009.

URBIZAGÁSTEGUI ALVARADO, R. A bibliometria no Brasil. Ciência da Informação, Brasília, v.13, p.41-105, 1984.

URBIZAGÁSTEGUI ALVARADO, R. La Bibliometría, Informetría, Cienciometría y otras "Metrías" en el Brasil. Encontros Bibli: revista eletrônica de biblioteconomia e ciência da informação, v.21, n.47, p.5166, 2016.

URBIZAGÁSTEGUI ALVARADO, R. Crecimiento de la literatura sobre bibliometria, informetria y cienciometria en el Brasil. RICI: Revista Ibero-americana de Ciencia da Informacao, v.10, n.1, p.6-31, 2017. 


\section{ANEXO A - Términos de búsqueda}

Acoplamiento bibliográfico

Análisis de citas

Arquivometría

Bibliometría

Bio-bibliometría

Brasil

Cienciometría

Circulación de la colección

Co-autoría

Co-citación

Colaboración científica

Colegios invisibles

Crecimiento de la literatura

Elitismo

Factor de impacto

Factor de inmediatismo

Frente de investigación

Indicadores bibliométricos

Indicadores cienciométrios

Indicadores en ciencia y tecnología

Índice de colaboración

Índice de inmediatismo

Índice de Pratt

Índice de Price

Índice $\mathrm{h}$

Informetría

Ley de Bradford

Ley de Goffman

Ley de Lotka

Ley de Price

Ley de Zipf

Netometría

Núcleo básico de periódicos

Obsolescencia de la literatura

Patentometría

Punto de transición

Redes sociales

Regla 80/20

Sitometría

Teoría epidémica

Vida media

Visibilidad

Webometría 


\section{ANEXO B - Bases de Datos consultadas}

ANPAD (Associação Nacional de Pós-Graduação e Pesquisa em Administração)

ArticleFirst

Biblioteca Virtual em Saúde

Biosis

BRAPCI

CAB Abstracts

DEDALUS: Banco de dados Bibliográficos da USP

Dialnet

Google

Google Scholar

HAPI

ICYT

INFOBILA de México

ISOC

JSTOR

Library and Information Science Abstract (LISA)

Library Literature \& Information Science Full Text

Library, Information Science \& Technology Abstracts (LISTA)

$\mathrm{LICl}(\mathrm{IBICT})$

Medline

PERI: Base de Dados de Periódicos (UFMG)

Periodica

Plataforma Lattes

Portal del Ricyt

Redalyc

Scielo Argentina

SciElo Brasil

Scielo Brasil

Scielo Chile

Scielo Colombia

Scielo México

Scielo Venezuela

Science Citation Expanded Index

Scopus

SPELL: Scientific Periodicals Electronic Library

Web of Science

WorldCat

y otras 120 bases de datos bibliográficas existentes en la biblioteca de ciencias de la Universidad de California en Riverside. 